\title{
Characterisation of short fatigue cracks in titanium alloy IMI 834 using X-ray microtomography
}

\author{
TP Chapman ${ }^{1}$, K M Kareh ${ }^{1}$, M Knop ${ }^{1}$, T Connolley², PD Lee ${ }^{3}$, MA Azeem³, \\ D Rugg ${ }^{4}$, TC Lindley $^{1}$, D Dye $^{1}$ \\ ${ }^{1}$ Department of Materials, Royal School of Mines, Imperial College London, Prince Consort \\ Road, London, SW7 2BP, UK \\ ${ }^{2}$ Diamond Light Source Ltd, Harwell Science and Innovation Campus, Didcot, OX11 ODE, \\ $U K$ \\ ${ }^{3}$ School of Materials, The University of Manchester, Oxford Road, M13 9PL, Manchester, \\ $U K$ \\ ${ }^{4}$ Rolls-Royce plc., Elton Road, Derby, DE24 8BJ, UK
}

\begin{abstract}
A first attempt at the three-dimensional evaluation of naturally initiated surface connected and internal fatigue cracks is presented. Fatigue crack initiation and growth in air and vacuum environments have been investigated through Xray microtomography in air and vacuum environments at elevated temperatures $\left(350^{\circ} \mathrm{C}\right)$, accompanied by post-mortem electron microscopy of the fracture surfaces. In vacuum $\left(<10^{-5} \mathrm{mbar}\right)$, multiple internal and surface-connected crack initiation was observed, but only the surface-connected cracks grew. In contrast, fewer cracks formed in air, these were mostly surface-connected and all were observed to grow. In all instances the initiation features were associated with globular primary $\alpha$. An improved fatigue life was found in vacuum, which was mostly a consequence of delayed initiation, but was also due to slower fatigue crack propagation. The non-propagation of internal cracks was taken to imply that even the good laboratory vacuum obtained here was insufficient to simulate the conditions obtained for an internal crack in a component. The crack shape evolved towards a semi-circular shape $a / c=1$ in air during fatigue crack growth, whilst the vacuum cracks remained semi-elliptical $(a / c \simeq 1.4)$. This was taken to imply that oxide-induced crack closure played a role in fatigue crack growth in air.
\end{abstract}

Keywords: Titanium, Fatigue, Tomography, Vacuum

\section{Introduction}

IMI834 is a near- $\alpha$ titanium alloy that is often used for high temperature compressor applications (up to $600^{\circ} \mathrm{C}$ [1]) as a lower-density alternative to nickel superalloys, whilst giving a significant temperature benefit over their $\alpha / \beta$ 
5 counterparts $\left(\mathrm{Ti}-6 \mathrm{Al}-4 \mathrm{~V}+200^{\circ} \mathrm{C}\right.$, Ti- $\left.6246+100^{\circ} \mathrm{C}\right)$, cumulatively leading to increased fuel efficiency. Reducing aeroengine fuel consumption improves overall aircraft efficiency, offering positive financial and environmental implications to airlines.

During operation, compressor disks experience a range of temperature from 10 maximum at the rim to minimum at the disk bore. A complex bimodal microstructure is developed to withstand both creep and fatigue mechanisms. IMI 834 is often used with $\sim 10-15 \%$ volume fraction of globular primary alpha, in a transformed beta matrix, in order to provide a well balanced creep-fatigue response [2, 3. However, compressor disks are often subjected to cold working 15 before entering service, in order to increase resistance to fatigue 44. This is achieved by surface treatment to produce compressive residual stresses at the surface. In the past this was most commonly achieved by shot peening, where the surface of the disk is bombarded by small spherical shot with enough force to produce dimples on the component service. More recently, laser shock peening has been implemented, using shockwave mechanics to produce a similar effect.

Low cycle fatigue is the most representative laboratory simulated regime for in-service flight cycles. Under these loading conditions, fatigue cracks are known to spend the majority of total life in the propagation phase [5]. Shot peening can retard both fatigue crack initiation and growth, thus significantly increas-

${ }_{25}$ ing the lifetime of the part. Fatigue cracks are eventually initiated subsurface and propagate internally before connecting to the component surface and the surrounding atmosphere [6]. The fatigue cracking mechanism and associated fatigue crack growth rates (FCGR) of internal features is poorly understood, and provides a major challenge regarding estimation of component life.

30

It is therefore vital that knowledge within this area is developed. Subsurface short fatigue cracks cannot be measured using the conventional potential drop method commonly utilised for crack growth rate measurements of surface breaking defects. At present, subsurface initiating cracks are widely simulated by testing and monitoring surface breaking fatigue cracks in a vacuum envi-

35 ronment. However, Hack and Leverant proposed a model in the early 1980s to explain a significant life debit observed from an internal initiation site in a large colony Ti-6Al-4V material under LCF loading [7. They proposed that the onset of basal slip and subsequent slip band formation promotes creation of a hydrostatic stress field at the tip of a blocked pile of dislocations. This in turn is 40 considered to attract increased levels of hydrogen by diffusion, facilitating cleavage of brittle hydride or local high hydrogen concentration phases [7. Hence, although many consider the FCGR of surface connected cracks in vacuum to be equivalent to that of internal features, it is not clear that this is an accurate representation and if existing lifing methods are conservative.

The present work demonstrates a first attempt, to our knowledge, at the direct measurement of a growing subsurface short fatigue crack at high temperature, using high-resolution X-ray microtomography techniques. A number of recent studies have used X-ray tomography as the principal experimental tool to investigate growth of short fatigue cracks [8, 9, 10, 11. Particularly,

50 Birosca et al. have previously undertaken three-dimensional characterisation of 
surface breaking fatigue cracks initiated from artificial notches, propagating in air at ambient temperatures [12. We aim to take this technique further, by comparing the development of naturally initiated surface and internal fatigue cracks at high temperature, in both air and vacuum environments, using X-ray

\section{Material and Experimental Procedures}

\subsection{Fatigue Testing}

The cylindrical fatigue specimens tested during this work were machined from the rim of IMI834 1 disc material, provided by Rolls-Royce plc. Figure 1(a) provides a schematic representation of the LCF test piece, with an overall length of $64.20 \mathrm{~mm}$. The small gauge diameter $(2.5 \mathrm{~mm})$ was introduced since the mechanical testing rig utilised a $5 \mathrm{kN}$ load cell and also so as to optimise the resolution in X-ray microtomography. A vacuum furnace was developed in order to conduct the high temperature fatigue tests, both in air and under

65 high vacuum conditions $\left(\sim 10^{-5} \mathrm{mbar}\right)$, at $350^{\circ} \mathrm{C}$. Air and vacuum samples were tested under the same constant stress amplitude loading conditions in the low cycle fatigue regime, using a triangular waveform with an $\mathrm{R}$ ratio of $\sim 0.1$ $\left(\sigma_{\max }=770 \mathrm{MPa}, \sigma_{\min }=70 \mathrm{MPa}\right)$. The vacuum furnace was designed for use during beamline experiments, therefore curved quartz windows were fitted

70 around $280^{\circ}$ of the furnace exterior, to allow the X-ray beam to pass in and out of the furnace, as shown in Figure 1(b) and (c). Prior to beam time, a number of samples were tested to failure to achieve an estimate for the average number of cycles to failure, in both air and vacuum environments. Table 1 gives the number of cycles to failure for samples tested at different stress ranges;

75 those samples monitored using tomography are also highlighted. The aim of the beamline experiment was to tomographically image the advancing crack throughout the propagation stage of fatigue life. Thus, for efficient use of time once on the beamline, samples were pre-cycled to various percentages of the estimated lives.

[Figure 1 about here.]

[Table 1 about here.]

\subsection{Synchrotron X-ray Tomography}

Limited angle X-ray micro-tomography measurements were carried out on beamline I12 (Joint Environmental, Engineering and Processing beamline) at

85 The Diamond Light Source Synchrotron, Oxfordshire, UK [13. LCF samples of interest were mounted inside the furnace with the $15 \mathrm{~mm}$ gauge length positioned in the centre of the quartz windows. For the duration of this experiment, the beamline's X-ray imaging detector was used to provide a resolution

${ }^{1}$ IMI834: Ti-5.8Al-4.0Sn-3.5Zr-0.7 Nb-0.5Mo-0.35Si-0.06C (wt.\%) 
of $1.3 \mu \mathrm{m} /$ pixel and a field of view of $3.32 \mathrm{~mm}$ (horizontal) by $2.80 \mathrm{~mm}$ (vertical). As per the preparatory offline tests, samples were cycled from $70-770 \mathrm{MPa}$ at $350{ }^{\circ} \mathrm{C}$ in situ. Imaging was undertaken after a specific number of fatigue cycles, by interrupting the fatigue experiment and holding at $500 \mathrm{MPa}$ (at temperature). Images were captured every $0.1^{\circ}$ using a beam energy of $65 \mathrm{keV}$, as the entire rig was rotated at a speed of $0.125^{\circ} \mathrm{s}^{-1}$. Since the design of the 95 vacuum furnace and fatigue rig restricted the scanning angle to $140^{\circ}\left( \pm 70^{\circ}\right)$, 1420 projections were captured per tomogram, including 10 dark field and 10 flat field images. An exposure time of $0.75 \mathrm{~s}$ per projection led to a scan time of approximately 20 minutes. From a fatigue perspective, it should be noted that titanium alloys demonstrate degraded fatigue properties under dwell loading conditions. It was for this reason that the load applied during scans (500 MPa) was well below the maximum fatigue load (770 MPa) and yield point (660 MPa), but still sufficient to open the crack in order to assist with crack imaging.

\subsection{Laboratory X-ray Tomography}

Due to time constraints associated with the beamline experiment, further scans were undertaken ex situ using a laboratory X-ray micro-tomography instrument at the Manchester X-ray Imaging Facility, Harwell, UK (Phoenix X-ray Systems \& Services). A compact tensile rig was developed that could be placed inside the Phoenix to apply a constant load to the sample throughout a scan, to hold the crack open to assist with image resolution. A $5 \mathrm{kN}$ load cell was 110 calibrated to provide a relationship between applied load, $F(\mathrm{~N})$, and voltage output, $V(\mathrm{mV})$.

The tensile crack opening rig for ex situ tomography scans is shown in Figure 1(d). The lower specimen grip screwed directly into the load cell which provided the voltage output. The specimen is enclosed within a $0.5 \mathrm{~mm}$ thick aluminium window, separating the upper and lower halves of the rig. A compressive load was applied to the aluminium window by manually screwing a nut down onto the threaded end of the upper specimen grip. An equal and opposite tensile force was therefore imparted to the specimen to open existing fatigue cracks during imaging. Application of torsional loads were prevented by the non-cylindrical design of the upper specimen grip. Prior to imaging, all specimens were stressed to $600 \mathrm{MPa}(\equiv-21.5 \mathrm{mV})$. All scans were carried out with a $100 \mathrm{kV}$ accelerating voltage, a $70 \mu \mathrm{A}$ current and an exposure time of $2 \mathrm{~s}$. Due to the cylindrical geometry of the fatigue sample, a $0.8 \mathrm{~mm}$ thick copper filter was used to assist with beam hardening corrections, by filtering out lower energy X-rays. By 125 rotating the sample through $360^{\circ}, 1000$ images were captured on a $990 \times 990$ pixel detector. The rig was positioned close to the target, in order to achieve a voxel size of $\sim 5 \mu \mathrm{m}^{3}$.

\subsection{Image Processing}

All synchrotron data sets were reconstructed using in-house software (DAWN ${ }_{130}$ Science) under development at The Diamond Light Source. The software used a special implementation of a filtered back projection algorithm, developed by 
a group at Manchester University [14. Data obtained from the laboratory Xray source were reconstructed using the software provided by Phoenix X-ray Systems \& Services (Phoenix DataOSX2rec). A number of voxel sized $\left(5 \mu^{3}\right)$ features were observed within vacuum sample LF006. To eliminate the possibility of analysing image artefacts, a filter was applied to exclude all features existing over less than 10 slices in the sample z-axis.

Further analysis of selected features was undertaken using the commercially available image processing software, Avizo 7.0. Voxels were counted using a 140 marching cube algorithm procedure, implemented within the software. Due to the limited angle during synchrotron data acquisition, and the evolving software, the reconstructions consisted of large artefacts, which required that the data sets were manually thresholded. For consistency, the images from the laboratory acquisition were also manually thresholded. 3D volumes were produced from the thresholded data before performing principal component analysis (PCA) in MATLAB to calculate crack lengths 15 .

PCA is a statistical procedure used to convert data points (pixels) into a set of linearly uncorrelated variables called principal components. Analysis of $3 \mathrm{D}$ data such as this requires three principal components for each data point;

150 thus three mutually orthogonal axes are defined. The first principal component accounts for as much variability in the data as possible. This component has been defined as the major axis. The second principal component is defined as the minor axis and is perpendicular to the major axis. These two axes comprise a plane, and in the case of $2 \mathrm{D}$ data sets, all data points could be projected onto this 155 plane to calculate scalar quantities such as length. A third principal component is required for the analysis of $3 \mathrm{D}$ data sets. This third axis is a normal vector of the plane comprised of the major and minor axis. With reference to Figure 2(b), it should be clear that for a semi-circular crack geometry, the major and minor axes are associated with the $2 c$ (surface crack length) and $a$ (crack depth) parameters respectively.

[Figure 2 about here.]

\subsection{Uncertainty in Measurements}

Uncertainty in crack length measurements is a function of the resolution, and thus is greater for the laboratory scans compared to the synchrotron data. Based on detection of a bright-dark-bright voxel feature, the estimated nominal uncertainty of a voxel of size $N$ microns is $3 N$. In the context of the present study, further sources of error may have arisen from manual thresholding of both synchrotron and laboratory data sets, as well as inconsistencies of crack opening displacement during scans, particularly between data sets obtained from 170 the synchrotron vs. the laboratory.

\subsection{Starting Material}

The microstructure of the alloy was examined using a Zeiss Auriga field emission gun scanning electron microscope (FEG-SEM) in the backscatter mode, using a $10 \mathrm{kV}$ accelerating voltage. Metallographic samples were prepared from 
the cross-section of the threaded ends of a fatigue specimen, well away from the fracture surface within the gauge length. The near-alpha IMI834 material demonstrated a bimodal microstructure; Figure 3(a). This consisted of globular primary alpha grains embedded within a lamellar transformed beta matrix, comprised of alpha laths; Figure 3(b). The fracture surfaces of failed low cycle 180 fatigue samples were analysed using the same microscope, this time in secondary electron imaging mode (SEI).

[Figure 3 about here.]

\section{Results}

\subsection{Mechanical Testing}

185 The monotonic stress-strain curve to failure at $350{ }^{\circ} \mathrm{C}$ in air is shown in Figure 4(a). The specimen used for this tensile test was the same as those used for fatigue tests, as shown in Figure 1(a). The $0.2 \%$ offset yield stress $\left(\sigma_{Y}\right)$ at $350{ }^{\circ} \mathrm{C}$ was approximately $660 \mathrm{MPa}$, with an associated failure stress of $795 \mathrm{MPa}$ $\left(\sigma_{F}\right)$. During the high-temperature tensile test, strain was measured using a high-temperature ceramic clip-on extensometer. Figure 4(b) shows the cyclic stress-strain curves for air and vacuum samples (LF015 and LF006 respectively). Initially, fatigue tests were undertaken using various stress ranges, with $\sigma_{\max }$ between $700-770 \mathrm{MPa}$ (Table 1 ). The $\mathrm{R}$ ratio was $\sim 0.1$. Since cracks were required to initiate naturally during the beamline experiment, a fatigue life $\left(N_{F}\right)$ of circa 10,000 cycles was desired from tests in air. This was achieved using a stress range of $70-770 \mathrm{MPa}$. The same loading conditions were applied (for consistency) during the vacuum tests.

[Figure 4 about here.]

The utilisation of a maximum stress of $770 \mathrm{MPa}$ resulted in macroscopic plasticity, giving low cycle fatigue behaviour and a life on the order of $10^{4}$ cycles. This impressive LCF performance is also found for operating temperatures at the rim on the order of $600^{\circ} \mathrm{C}$; e.g. at $550^{\circ} \mathrm{C}$ where the yield stress is $\sim 550 \mathrm{MPa}$ an LCF life of $10^{4}$ cycles is obtained with a stress of $665 \mathrm{MPa}$ [16].

Figure 4(b) shows cyclic data for cycles 1 and 5000 in both air and vacuum environments. Cyclic strain accumulation was observed between cycle 1 and 5000 in both air $\left(\epsilon_{\max } 4.4-4.8 \%\right)$ and vacuum $\left(\epsilon_{\max } 1.9-2.2 \%\right)$. It is clear the the overall levels of strain experienced in air were more than twice those experienced in vacuum, under the same applied stress range and temperature. However, the strain accumulation per cycle was very similar, $0.7 \%$ in air and $0.6 \%$ in vacuum.

210 Finally, only minimal hysteresis was observed during cycle 1, with almost fully reversed strain apparent in cycle 5000, consistent across both environments. The observed plastic strain was also evident (post-failure) from the reduced diameter of the specimen gauge cross-section. 


\subsection{Fatigue at $350^{\circ} \mathrm{C}$ in air}

215 tiation and propagation, using X-ray microtomography. The first specimen, LF015, was fatigued in air to 9000 cycles offline and then monitored in situ using synchrotron tomography. The first fatigue crack to initiate was feature 5 (Table 2); it was detected at 9217 cycles and monitored for $>2500$ cycles as $500 \mu \mathrm{m}$ in length. The sample failed after 12149 cycles when feature 5 reached a critical length. Figure 5 shows the measured crack size data for feature 5 plotted against the number of cycles. As shown in Figure 2(b), the major data $(2 c)$ corresponds to the surface crack length and the minor data $(a)$ to the crack 225 depth.

[Table 2 about here.]

[Figure 5 about here.]

A power law fit was calculated for both the major and minor data sets shown in Figure 5(a). By integrating the Paris Law and comparing against 230 the fitted data, power values of $m$ were estimated as 1.8 and 1.6 for the major and minor data respectively. The gradient of each curve is shown to increase with number of cycles, demonstrating an increase in crack growth increment per cycle (increasing FCGR). Figure 5(b) shows the evolution of the crack shape ratio $a / c$. Geometrically, for a semi-circular crack, $c=a$; Figure 2(b) and (c). conformed to this criterion between 11000 and 12000 cycles $(\mathrm{a} / \mathrm{c} \sim 1)$. This increment of crack growth also corresponds to the longest cracks and highest growth rates. During slower growth $(<10500$ cycles $)$, the ratio was closer to 1.8 , equivalent to a narrower aspect ratio morphology.

240 The synchrotron tomography experiment was optimised for image resolution $(1.3 \mu \mathrm{m})$, which meant accepting a compromise regarding the vertical field of view $(2.8 \mathrm{~mm})$. Scanning the entire specimen gauge $(15 \mathrm{~mm})$ was inefficient regarding the strict time constraints imposed during beamline experiments. Thus, only the dominant crack was monitored in situ once it had been identified. Following beam time, the entire gauge length of air sample LF015 was scanned ex situ using the laboratory source. Table 2 shows the crack parameters for each of the 10 features resolved within the air specimen after 11914 cycles. Although feature 5 is clearly the dominant and largest defect, the sample did contain many other surface connected defects of significant size $(100-370 \mu \mathrm{m})$. At this 250 stage of the specimen life no internal cracks were observed. The longitudinal (a) and cross-sectional (b) positions of each feature within the specimen gauge volume are represented schematically in Figure6. Although the features appear to be clustered on one side of the specimen, which may indicate sample misalignment, a more uniform feature distribution was evident in sample LF006, 255 tested in vacuum; refer to Figure 7 .

[Figure 6 about here.] 
[Figure 7 about here.]

Figure 8 shows the reconstructed volumes of the surface breaking crack, tested and monitored in air in situ. Between cycles 9217 and 10564 the crack

260 low FCGR observed with reference to Figure 5 over the same cyclic range. At 11914 cycles, the geometry of the feature clearly demonstrates the 1:1 a/c ratio as observed from Figure 5 .

Feature 5 was monitored in situ until 11914 cycles, before cycling to failure demonstrating the position of the initiation site $(\diamond-$ feature 5$)$, an area of fatigue striations $(\square-\mathrm{e})$ and a fatigue crack origin initiated just beneath the specimen surface $(\triangle-\mathrm{f})$. Feature 5 was always observed to be surface-connected during the tomography experiment, and this is reiterated by the surface connected unclear whether the secondary initiation site observed fractographically (f), can be related to any of the other cracks observed by X-ray tomography, since it appears to have initiated subsurface, before growing to connect to the surface prior to detection.

[Figure 8 about here.]

[Figure 9 about here.]

The striated region of the crack $(a=395 \mu \mathrm{m})$ was just larger than the crack measured by X-ray tomography only 235 cycles prior to failure. Therefore the microvoid coalescence region corresponds to the final failure. With reference 280 to Figure $9(\mathrm{~h})$ there is evidence to suggest the voids were crystallographic in nature, since the band of voids shown in (h) appear to have association with the width of the transformed lamellar microstructure. Similarly, the initiating facet shown in (b) and (c) has dimensions equivalent to those of the primary alpha grains.

\subsection{Fatigue at $350^{\circ} \mathrm{C}$ in vacuum}

The second specimen monitored during this study was denoted sample LF006. This specimen was fatigued in vacuum to 12000 cycles, which was estimated from sample LF031 to be $\sim 85 \%$ of the total life; refer to Table 1. As for air sample LF015, sample LF006 was (initially) monitored in situ using synchrotron tomography. However, after cycling in situ for more than 6500 cycles without promoting fatigue crack initiation, beamline time constraints required that work was continued ex situ, using laboratory based X-ray tomography instrumentation. This involved fatigue cycling in vacuum at $350{ }^{\circ} \mathrm{C}$ before scanning in the laboratory CT-unit in room temperature air under tension $(\sim 3 \mathrm{kN})$; see Fig295 ure 1(d). A drawback was that the resolution was reduced from $1.3 \mu \mathrm{m}$ (synchrotron) to $5.0 \mu \mathrm{m}$ in the laboratory. However, a positive consequence was the ability to scan the complete sample gauge length, so as to monitor the growth of all cracks within the volume. 
The first feature was not detected until 19726 cycles, but unlike air sample initiated internally and had remained disconnected from the specimen surface. Since all samples were manufactured from aerospace-grade titanium and prescanned at zero cycles, it is considered highly improbable the internal features have initiated from melt defects/inclusions or internal pores. The complete 305 gauge length of sample LF006 was monitored ex situ for a further 3000 cycles, with additional features identified at each scanning interval. Table 3 provides the crack parameters for all features resolved within the vacuum specimen at each scan. The longitudinal (a) and cross-sectional (b) position of each feature within the specimen gauge volume is represented schematically in Figure section and a number of internal features were observed to have initiated well below the specimen surface. Another contrast to air sample LF015 is observed from the crack parameters demonstrated in Table 3 . The values presented suggest that the majority of the surface and internal features in LF006 underwent Therefore it appears that compared to fatigue in air, cycling in a vacuum environment results in an increased number of initiating cracks but less propagation of non-dominant features.

[Table 3 about here.]

320

Features 22 and 23 are highlighted within Table 3 since they were the dominant (surface) fatigue cracks, whose growth cumulatively resulted in the final failure of the specimen. Figure 10 shows the measured crack size data for features 22 and 23 plotted against the number of cycles. The quantity of data gathered for vacuum sample LF006 was far less extensive than desired, and was 325 an indirect shortcoming of the labour intensive ex situ data acquisition method. As for air sample LF015, a power law fit was calculated for both the major and minor data sets. Power values of $m$ were estimated as 1.8 and 1.6 for the major and minor data for feature 22 and 1.8 in both instances for feature 23. With so few data points, the curve fit is poor and does not provide much additional in-

330 sight, however it can be observed that for both features, each crack appeared to be dormant from 19726-21726 cycles but propagated from $100 \mu \mathrm{m}$ to $>350 \mu \mathrm{m}$ in the final 1000 monitored cycles. The sample failed during the next increment of offline fatigue loading; $\mathrm{N}_{\mathrm{f}}=23204$ cycles. Figures 10 (c) and (d) provide the crack parameter ratios for features 22 and 23, respectively. Feature 22 exhibits 335 a similar trend to LF015, with the a/c ratio decreasing with number of cycles, but did not reach a 1:1 aspect ratio. By contrast, feature 23 shows a gradual incline from 1.2 to 1.5 .

[Figure 10 about here.]

Figure 11 shows the reconstructed volumes of the vacuum surface breaking 340 
are also clearly illustrated in the reconstructions shown in Figure 11 . For feature 22, Figure 11(a), the crack appeared to propagate only between 21726 and 22726 cycles. This was also the case for feature 23, Figure 11(b). The observed morphology of each of the features also suggests that the propagated cracks possessed a semi-elliptical shape, rather than semi-circular, thus reiterating the findings of Figures 10 (c) and (d). The ex situ nature of the crack growth measurements for the vacuum sample led to larger cycle block increments between scans, than for the in situ measurements on the beamline.

[Figure 11 about here.]

After scanning at $N=22726$ cycles the next increment of fatigue loading was applied; the sample failed after an additional 478 cycles $\left(N_{f}=23204\right.$ cycles). Figure 12 provides an overview of the fracture surface of vacuum sample LF006, with areas corresponding to features 22 and 23 demonstrated by the white dashed border; Figure 12(a). Particularly for the larger initiation site (feature 23), the semi-elliptical morphology of the crack remained during final propagation to failure. As for air sample LF015, both surface vacuum fatigue origins were observed as clusters of facets, each of a length scale equivalent to globular primary alpha grains; Figure 12(b) and (c). Striations were resolved as the crack extended, as shown by Figure 12 (d), the location of which is denoted by the square symbol in Figure 12 (a).

[Figure 12 about here.]

With reference to Table 3 it is evident that a significant number of internal cracks were also resolved within vacuum sample LF006, using laboratory X-ray tomography. Figure 13 shows the reconstructed volume of internal feature 17 365 from the $\mathrm{x}-\mathrm{y}$ cross-section perspective (left) and the $\mathrm{z}-\mathrm{y}$ longitudinal perspective (right). The dimensions of the volume demonstrated in Figure 13 are equivalent to those of a globular primary alpha grain in the IMI 834 microstructure, as was the case for the surface initiation facet origins in air and vacuum. Figure 14(a) shows the measured crack size data for feature 17 plotted against the number of cycles; this internal crack was resolved after 20726 cycles. Considering the $\mathrm{y}$-axis scale, it is apparent that the subsurface feature did not undergo rapid propagation during the monitored period, growing by only $20-30 \mu \mathrm{m}$ along the major and minor directions (within the uncertainty range). The accelerated growth occurring in the final 1000 monitored cycles for features 22 and 23 was 375 not observed for this, or any, internal feature. As for the dominant features 22 and 23, the power fit should be considered an estimate, with a value $m=$ 1.4 found for both the major and minor crack axes. Figure 14(b) indicates a consistent $a / c$ ratio, which remains largely unchanged for the duration of the monitored cycles.

[Figure 13 about here.]

[Figure 14 about here.] 
For air sample LF015, it was previously stated that beyond the semi-circular fatigue initiation/propagation site, the remainder of the fracture surface was observed to have formed by microvoid coalescence. This observation was consistent

\section{Discussion}

\subsection{Synchrotron vs. laboratory source tomography}

420

Air sample LF015 was monitored in situ using synchrotron tomography. Due to time constraints on the beamline, only the primary fatigue crack was monitored in situ. Following beam time, the entire gauge length $(15 \mathrm{~mm})$ of the specimen was scanned ex situ using a laboratory tomography source; data for 
feature 5 was therefore captured using both imaging techniques. These data sets were processed as per the method described in Section 2.4 upon analysis it was determined that parameters $2 c$ and $a$ were calculated to be $556 \mu \mathrm{m}$ and $286 \mu \mathrm{m}$ from the synchrotron and $557 \mu \mathrm{m}$ and $271 \mu \mathrm{m}$ from the laboratory source. The variation between the two data sets is minimal, and remains within the nominal uncertainty ( \pm 3 voxels). For this reason, data acquired from either source is 430 considered equivalent and consistent, and thus results are directly comparable. The decision to utilise the synchrotron over the laboratory X-ray source (or vice-versa), will be determined by the priority placed on the data, whether that be with regards to resolution, or flexible availability of equipment, etc.

\subsection{Initiation and propagation}

The improved fatigue life of metals in vacuum was initially identified during the 1960s. An increased fatigue limit was observed for titanium alloys tested at pressures below $10^{-6}$ mbar, compared with laboratory air conditions [17. However, it remains unclear as to whether the reduced fatigue performance in high temperature air environments is a consequence of deleterious effects upon

440 the initiation or propagation phases specifically, or a combination of both. In the present work two cylindrical IMI 834 specimens were tested at $350^{\circ} \mathrm{C}$ using identical fatigue loading conditions; the only disparity in the testing condition was the operating environment - LF015 was tested in air, LF006 in vacuum $\left(<10^{-6} \mathrm{mbar}\right)$. A number of observations can be made.

${ }_{445}$ X-ray microtomography enabled three-dimensional observation of the fatigue crack initiation process. Crack initiation is defined as the initiation of the first resolved feature within the sample (after growth exceeds the detection limit). Examination of air sample LF015 demonstrated initiation after 9217 cycles, equivalent to $76 \%$ of the total fatigue life whereas vacuum sample LF006 initiated a fatigue crack after 19726 cycles, equivalent to $85 \%$ of the total life; the difference in propagation life was small (2932 vs. 3478 cycles). These observations provide evidence to suggest that improved fatigue life $(\sim 12000$ to 23000 cycles) is mostly related to delayed crack initiation in vacuum, which is consistent with findings from Demulsant and Mendez [17] and Sugano et al. [18].

From post-mortem examination of the fractographic surface, facet-like features of the length scale of globular primary alpha grains were identified at the origins of air and vacuum fracture surfaces, and at internal features. Therefore a picture emerges that the weakest locations in the microstructure are the globular primary $\alpha$ grains. However, in the high-life vacuum cracking situation, these crack initiation sites do not necessarily grow - crack initiation and growth is always preferred at a surface, preferably one where air is available. Therefore profuse subsurface cracking is observed in the vacuum sample.

FCGRs in air and vacuum were compared at a crack length of $200 \mu \mathrm{m}$, in air and vacuum. It was demonstrated that the growth rate in air was (1.6 465 times) higher than at an equivalent crack size in vacuum; consistent with existing literature on the subject [6, 18, 19]. Further, information extracted from examination of the fracture surface was compared to tomographic observations; from the present findings the elucidation of striation formation per fatigue cycle 
was confirmed for a vacuum environment but refuted for an air environment (in the LCF regime). Ritchie et al. demonstrate that this hypothesis completely breaks down in the high cycle fatigue regime, since they determined that 40000 cycles was required to produce one fatigue striation [20].

Hydrogen (from water vapour) and oxygen are considered aggressive species and are damaging to titanium at elevated temperatures [17, 21. The increased

475 fatigue strength and reduced FCGR in vacuum is often attributed to the absence of a chemisorbed oxide film on newly generate crack surfaces [21]. In air, active gases have easy access to exposed titanium at the crack tip, particularly at the maximum crack tip opening displacement 22. As the surface oxide builds up, the adherent oxide layer restricts slip reversibility upon load reversal 5 ]

${ }_{480}$ leading to reduced plasticity. In vacuum the newly exposed crack tip can be kept comparatively clean; absence of oxide debris leads to fully reversed slip (often enhanced by internal heating), increased plasticity, crack tip blunting and a lower FCGR [18, 23].

\subsection{Internal Cracking}

${ }_{485}$ Titanium alloys are known to be susceptible to internal fatigue cracking (subsurface crack initiation) at high temperatures in both air and vacuum environments 24. Internal fatigue origins are most commonly associated with $\mathrm{HCF}$ loading, but internal LCF cracks have also been documented [17, 6]. Subsurface fatigue cracks are considered to exist in a vacuum environment, since they are not in contact with the external atmosphere and are thus not exposed to gas adsorption [25]. Demulsant and Mendez suggest that internal crack initiation is in competition with surface damage, which would be affected by both environment and stress. It is proposed that internal damage is more likely to lead to internally initiated failure at low applied stresses or in an inert atmosphere [17. Of course the likelihood for internal initiation increases further by the application of surface compressive residual stresses (laser shock peening).

Observations from the present work demonstrate that under equivalent loading conditions fatigue in air demonstrated primarily surface connected initiations sites, whereas a combination of internal and surface connected origins 500 were observed after testing in vacuum, in agreement with work by Demulsant and Mendez [17]. Further, the surface connected features in the air environment all propagated during fatigue cycling, whereas several of the surface and internal origins in the vacuum environment appear to become periodically retarded during the propagation phase (Features 22 and 23), whilst other features once initiated did not undergo propagation. It is also clear that a surface-connected crack growing in vacuum conditions grows faster than a subsurface crack. Sinha and Larsen [6] consider the vacuum levels needed to simulate internal fatigue crack growth. They demonstrated that even the most state-of-the-art vacuum pumps are orders of magnitude away from truly simulating internal fatigue 510 cracking in titanium alloys [6. During the present work, a vacuum on the order of $10^{-5}-10^{-6}$ mbar was achieved from a commercially available turbo pump, and an in-house bespoke built vacuum furnace. Although many internal cracks initiated within the vacuum tested sample (LF006), it was two surface cracks 
that caused final specimen failure, which may imply agreement with Sinha, on the effective closure increases, also experiencin a mismatch in crack face asperities with build up of oxidation product 32 , eventually reducing the internal FCGR and resulting in a semi-circular crack $(a / c=1)$.

Figure 15(a) shows an $x-z$ section through the primary surface-connected air-initiating fatigue crack in LF015. Image (a) was captured from a synchrotron source with a resolution of $1.3 \mu \mathrm{m}$, and looks to be crystallographic in appearance and has undergone extensive crack branching. There is also evidence of small secondary cracks, presumably formed ahead of the crack tip, which have 555 since linked up with the main crack as this primary crack has propagated. Birosca et al. 12 deduce that in $\alpha / \beta$ alloy Ti-6246, crack bifurcation occurs from interaction of the crack tip with the microstructure; i.e. diverting the crack at prior beta grain boundaries. We expect this is also the case for the 
duplex microstructure near-alpha alloy IMI 834 used in the current study. Here, high misorientations between the $\alpha$ lamellae are likely to cause crack path diversion and undulation as seen in Figure 15(a) [12. Effective crack closure is also considered to increase with further crack deflection during propagation [17, specifically for short cracks where the deflection is comparable to the crack opening displacement 33 .

[Figure 15 about here.]

Figures 15 (b-c) show $x-z$ sections through the specimen tested in vacuum (LF006), for the primary surface connected fatigue cracks, and an example of an internally initiating fatigue crack. The drawback of laboratory source data acquisition is demonstrated by (b) and (c) in terms of the reduced resolution; however it remains possible to observe crack deviation of the primary surface connected vacuum crack (b). Figure 15(c) displays a 2D section of a short internal crack (Feature 17 LF006).

\section{Conclusions}

This work represents a first attempt at the three-dimensional characterisation of naturally initiated surface connected and internal fatigue cracks, in air and vacuum environments at elevated temperatures. The following conclusions can be drawn:

1. X-ray microtomography has the capability to detect internal fatigue cracks and follow their evolution, which will promote increased understanding of the micromechanisms of internal fatigue cracking, rather than relying on data from surface-connected fatigue crack growth in a laboratory vacuum.

2. In all instances (air/vacuum and surface/internal), the mechanism of crack initiation on the fracture surface was by facet formation, on the scale of globular primary alpha grain size (15-50 $\mu \mathrm{m}$ diameter).

3. The fatigue life was longer in vacuum than air and at the same crack size the fatigue crack growth rate was higher in air than vacuum.

4. In air, the initiation life was 9217 cycles, equivalent to $76 \%$ of the total life $\left(N_{f}=12149\right)$, whereas in vacuum initiation occurred after 19726 cycles, equivalent to $85 \%$ of the total fatigue life $\left(N_{f}=23204\right)$.

5. The improved fatigue response in vacuum arose mostly from delayed initiation, but also from slower propagation of fatigue cracks in a vacuum environment.

6. In air, when $\sigma_{\max }>\sigma_{\mathrm{y}}$ (LCF regime) several surface fatigue cracks initiated, which all propagated during fatigue cycling.

7. LCF loading in vacuum resulted in the formation of many internal and surface-connected cracks. Only a few of these propagated, which were all surface-connected.

8. The crack shape evolved towards a semi-circular shape $a / c=1$ in air during fatigue crack growth, whilst the surface-connected vacuum cracks remained semi-elliptical $(a / c \simeq 1.4)$. This suggests that oxide-induced crack closure plays a role in fatigue crack growth in air. 


\section{Acknowledgements}

The laboratory scans were performed at the Research Complex at Harwell, funded in part by the EPSRC (EP/I02249X/1). Anna Radecka and Peter Tym-

605 thank Chedtha Puncreobutr for access to his PCA code and general assistance with PCA analysis, and Kate Fox from Rolls-Royce plc for provision of material. Funding from EPSRC (grants EP/H004882/1 and EP/K034332/1, plus a DTA CASE conversion EP/J500239/1 for T.P.C) is also gratefully acknowledged, along with DLS synchrotron beam time (Experiment EE8942).

\section{References}

[1] H.-J. Christ, Effect of environment on thermomechanical fatigue life, Mater. Sci. Eng. A 468-470 (2007) 98-108.

[2] K. Prasad, P. Karamched, A. Bhattacharjee, V. Kumar, K. Bhanu Sankara Rao, Sundararaman, Electron back scattered diffraction characterisation of thermomechanical fatigue crack propagation of near $\alpha$ titanium alloy Timetal 834, Mater. Des. 65 (2015) 297-311.

[3] S. Hardt, H. Maier, H.-J. Christ, High-temperatyre fatigue damage mechanisms in near- $\alpha$ titanium alloy IMI 834, Int. J. Fatigue 21 (1999) 779-789.

[4] B. Sahoo, R. Satpathy, K. Prasad, S. Ahmed, V. Kumar, Effect of shot peening on low cycle fatigue life of compressor disc of typical fighter class aero-engine, Procedia Eng. 55 (2013) 144-148.

[5] S. Suresh, Fatigue of Materials, second ed., Cambridge University Press, 1998.

[6] V. Sinha, J. Larsen, Vacuum levels needed to simulate internal fatigue crack growth in titanium alloy and nickel-base superalloys: thermodynamic considerations, Metall. Mater. Trans. A 43A (2012) 3433-3441.

[7] J. Hack, G. Leverant, The influence of microstructure on the susceptibility of titanium alloys to internal hydrogen embrittlement, Metall. Mater. Trans. A 13 (1982) 1729-1738.

[8] E. Ferrié, J.-Y. Buffière, W. Ludwig, 3D characterisation of the nucleation of a short fatigue crack at a pore in a cast $\mathrm{Al}$ alloy using high resolution synchrotron microtomography, Int. J. Fatigue 27 (2005) 1215-1220.

[9] M. Herbig, A. King, P. Reischig, H. Proudhon, E. M. Lauridsen, J. Marrow, J.-Y. Buffière, W. Ludwig, 3-D growth of a short fatigue crack within a polycrstallnie microstructure studies using combined diffraction and phasecontrast X-ray tomography, Acta Mater. 59 (2011) 590-601. 
[10] A. King, W. Ludwig, M. Herbig, J.-Y. Buffière, A. Khan, N. Stevens, T. Marrow, Three-dimensional in situ observations of short fatigue crack growth in magnesium, Acta Mater. 59 (2011) 6761-6771.

[11] W. Ludwig, J.-Y. Buffière, S. Savelli, P. Clotens, Study of the interaction of a short fatigue crack with grain boundaries in a cast $\mathrm{Al}$ alloy using $\mathrm{X}$-ray microtomography, Acta Mater. 51 (2003) 585-598.

[12] S. Birosca, J.-Y. Buffière, F. Garcia-Pastor, M. Karadge, L. Babout, M. Preuss, Three-dimensional characterisation of fatigue cracks in Ti-6246 using X-ray tomography and electron backscatter diffraction, Acta Mater. 57 (2009) 5834-5847.

[13] M. Drakopoulos, T. Connolley, C. Reinhard, R. Atwood, O. Magdysyuk, N. Vo, M. Hart, L. Connor, B. Humphreys, G. Howell, S. Davies, T. Hill, G. Wilkin, U. Pedersen, A. Foster, N. De Maio, M. Basham, F. Yuan, K. Wanelik, I12: the joint engineering, envrionment and processing (JEEP) beamline at diamond light source, J. Synchrotron Radiat. 22 (In Press) DOI: $10.1107 / \mathrm{S} 1600577515003513$.

[14] S. Titarenko, V. Titarenko, A. Kyrieleis, P. Withers, A priori information in a regularized sinogram-based method for removing ring artefacts in tomography, J. Synchrotron Radiat. 17 (2010) 540-549.

[15] C. Puncreobutr, P. Lee, R. Hamilton, A. Phillion, Quantitative 3D characterisation of solidification structure and defect evolution in Al alloys, JOM 64 (2012) 89-95.

[16] G. Welsch, R. Boyer, E. Collings (Eds.), Materials Properties Handbook: Titanium Alloys, ASM International, 1994.

[17] X. Demulsant, J. Mendez, Influence of environment on low cycle fatigue damage in Ti-6Al-4V and Ti 6246 titanium alloys, Mater. Sci. Eng. A 219 (1996) 202-2111.

[18] M. Sugano, S. Kanno, T. Satake, Fatigue behaviour of titanium in vacuum, Acta Metall. 37 (1989) 1811-1820.

[19] M. Bache, W. Evans, M. McElhone, The effects of environment and internal oxygen on fatigue crack propagation in Ti-6Al-4V, Mater. Sci. Eng. A A234-A236 (1997) 918-922.

[20] R. Ritchie, D. Davidson, B. Boyce, J. Campbell, O. Roder, High cycle fatigue of Ti-6Al-4V, Fatigue Fract. Eng. Mater. Struct. 22 (1999) 621631.

[21] N. Grinberg, The effect of vacuum on fatigue crack growth, Int. J. Fatigue (1982) 83-95. 
[22] W. Evans, J. Jones, S. Williams, The interactions between fatigue, creep and environmental damage in Ti 6246 and Udimet 720Li, Int. J. Fatigue 27 (2005) 1473-1484.

[23] Z. Ismarrubie, H. Yussof, M. Sugano, Fatigue damage mechanism of titanium in vacuum and in air, Procedia Eng. 41 (2012) 1559-1565.

[24] D. Neal, P. Blenkinsop, Internal fatigue origins in $\alpha-\beta$ titanium alloys, Acta Metall. 24 (1976) 59-63.

[25] H. Oguma, T. Nakamura, Fatigue crack propagation properties of Ti-6Al$4 \mathrm{~V}$ in vacuum environments, Int. J. Fatigue 50 (2013) 89-93.

[26] W. Elber, The significance of fatigue crack closure, Damage Tolerance in Aircraft Structures: ASTM Special Technical Publication 486 (1971) 230-242.

[27] N. Limodin, J. Réthoré, J.-Y. Buffière, A. Gravouil, F. Hild, S. Roux, Crack closure and stress intensity factor measurements in nodular graphite cast iron using three-dimensional correlation of laboratory X-ray microtomography images, Acta Mater. 57 (2009) 4090-4101.

[28] N. Limodin, J. Réthoré, J.-Y. Buffière, F. Hild, S. Roux, W. Ludwig, J. Rannou, A. Gravouil, Influence of closure on the 3D propagation of fatigue cracks in a nodular cast iron investigated by X-ray tomography and 3D volume correlation, Acta Mater. 58 (2010) 2957-2967.

[29] K. Khor, J.-Y. Buffière, W. Ludwig, I. Sinclair, High resolution x-ray tomography of micromechanisms of fatigue crack closure, Scr. Mater. 55 (2006) 47-50.

[30] H. Toda, I. Sinclair, J.-Y. Buffière, E. Maire, T. Connolley, M. Joyce, K. Khor, P. Gregson, Assessment of the fatigue crack closure phenomenon in damage-tolerant aluminium alloy by in-situ high-resolution synchrotron X-ray microtomography, Philos. Mag. 83 (2003) 2429-2448.

[31] K. Prasad, S. Abhaya, G. Amarendra, V. Kumar, K. Rajulapati, K. Bhanu Sankara Rao, Fatigue crack growth behaviour of a near $\alpha$ titanium alloy Timetal 834 at $450^{\circ} \mathrm{C}$ and $600^{\circ} \mathrm{C}$, Eng. Fract. Mech. 102 (2013) 194-206.

[32] R. Nalla, B. Boyce, J. Campbell, J. Peters, R. Ritchie, Influence of microstructure on high-cycle fatigue of ti-6A)l-4V: Bimodal vs. lamellar structures, Metall. Mater. Trans. A 33 (2002) 899-918.

[33] X.-P. Zhang, J.-C. Li, C. Wang, L. Ye, Y.-W. Mai, Prediction of short fatigue crack propagation behaviour by characterisation of both plasticity and roughness induced crack closures, Int. J. Fatigue 24 (2002) 529-536. 


\section{List of Tables}

1 Low cycle fatigue test parameters and resulting fatigue lives at a stress ratio, $\mathrm{R} \sim 0.1 . \ldots \ldots \ldots \ldots \ldots \ldots$

715

2 Crack sizes for air sample LF015 after 11914 fatigue cycles, where $2 c=$ surface length and $a=$ depth. Features 1 to 10 from top to bottom of gauge length; refer to Figure 6 (* indicates to the initiating feature resulting in final failure). . . ....... 21

3 Crack sizes for vacuum sample LF006, where $2 c=$ surface length and $a$ =depth. Features 1 to 24 from top to bottom of gauge

720 length; refer to Figure 7 (* indicates to the initiating features resulting in final failure)............... 22 


\begin{tabular}{c|c|c|c|c} 
Specimen & $\sigma_{\max }$ & Environment & $N_{f}$ & Tomography \\
\hline LF016 & 700 & Air & 17977 & - \\
LF008 & 740 & Air & 16715 & - \\
LF026 & 770 & Air & 9402 & - \\
LF015 & 770 & Air & 12149 & Synchrotron \\
LF031 & 770 & Vacuum & 14372 & - \\
LF006 & 770 & Vacuum & 23204 & Laboratory \\
\hline
\end{tabular}

Table 1: Low cycle fatigue test parameters and resulting fatigue lives at a stress ratio, $\mathrm{R} \sim 0.1$. 


\begin{tabular}{c|c|cc|}
\multirow{2}{*}{ Feature ID } & Description & \multicolumn{2}{|c|}{ Crack Size $( \pm 5 \mu \mathrm{m})$} \\
& & $2 c$ & $a$ \\
\hline 1 & Surface & 258 & 167 \\
2 & Surface & 248 & 115 \\
3 & Surface & 158 & 97 \\
4 & Surface & 266 & 136 \\
$5^{*}$ & Surface & $\mathbf{5 5 7}$ & $\mathbf{2 7 1}$ \\
6 & Surface & 133 & 96 \\
7 & Surface & 155 & 115 \\
8 & Surface & 370 & 138 \\
9 & Surface & 235 & 144 \\
10 & Surface & 203 & 147
\end{tabular}

Table 2: Crack sizes for air sample LF015 after 11914 fatigue cycles, where $2 c=$ surface length and $a$ =depth. Features 1 to 10 from top to bottom of gauge length; refer to Figure 6 (* indicates to the initiating feature resulting in final failure). 


\begin{tabular}{|c|c|c|c|c|c|c|c|c|c|c|c|}
\hline \multirow{3}{*}{ Feature ID } & \multirow{3}{*}{ Description } & \multicolumn{10}{|c|}{ Crack Size $( \pm 15 \mu \mathrm{m})$} \\
\hline & & \multicolumn{2}{|c|}{18726 cycles } & \multicolumn{2}{|c|}{19726 cycles } & \multicolumn{2}{|c|}{20726 cycles } & \multicolumn{2}{|c|}{21726 cycles } & \multicolumn{2}{|c|}{22726 cycles } \\
\hline & & $2 c$ & $a$ & $2 c$ & $a$ & $2 c$ & $a$ & $2 c$ & $a$ & $2 c$ & $a$ \\
\hline 1 & Subsurface & - & - & $1-$ & - & $1-$ & - & - & - & 97 & 54 \\
\hline 2 & Subsurface & - & - & 65 & 62 & 68 & 65 & $\begin{array}{l}60 \\
60\end{array}$ & 54 & 72 & 66 \\
\hline 3 & Surface & - & - & $\begin{array}{l}1- \\
1\end{array}$ & - & $1-$ & - & - & - & 96 & 57 \\
\hline 4 & Surface & - & - & $1-$ & - & $1-$ & - & 64 & 50 & 114 & 85 \\
\hline 5 & Surface & - & - & $1-$ & - & $1-$ & - & $1-$ & - & 77 & 55 \\
\hline 6 & Subsurface & - & - & $1-$ & - & $1-$ & - & $\begin{array}{l}70 \\
70\end{array}$ & 54 & 85 & 64 \\
\hline 7 & Surface & - & - & $1-$ & - & $1-$ & - & $\begin{array}{l}47 \\
4\end{array}$ & 20 & 108 & 62 \\
\hline 8 & Surface & - & - & $1-$ & - & $1-$ & - & $\begin{array}{l}43 \\
:\end{array}$ & 22 & 133 & 129 \\
\hline 9 & Subsurface & - & - & $1-$ & - & $1-$ & - & 35 & 22 & 84 & 61 \\
\hline 10 & Surface & - & - & 107 & 56 & 125 & 95 & 133 & 56 & 187 & 107 \\
\hline 11 & Subsurface & - & - & 62 & 31 & 73 & 57 & $\begin{array}{l}68 \\
68\end{array}$ & 37 & $\begin{array}{l}86 \\
8\end{array}$ & 64 \\
\hline 12 & Surface & - & - & 145 & 147 & 158 & 126 & 175 & 136 & 336 & 262 \\
\hline 13 & Surface & - & - & 109 & 79 & 134 & 93 & 110 & 79 & 284 & 207 \\
\hline 14 & Subsurface & - & - & - & - & - & - & 66 & 34 & 90 & 66 \\
\hline 15 & Subsurface & - & - & $1-$ & - & $1-$ & - & - & - & 101 & 42 \\
\hline 16 & Surface & - & - & $1-$ & - & $1-$ & - & i - & - & $\begin{array}{l}91 \\
:\end{array}$ & 63 \\
\hline 17 & Subsurface & - & - & $1-$ & - & $\begin{array}{ll}1 & 94\end{array}$ & 59 & $\begin{array}{l}118 \\
118\end{array}$ & 73 & 131 & 82 \\
\hline 18 & Surface & - & - & 130 & 93 & 152 & 99 & 151 & 95 & 245 & 149 \\
\hline 19 & Surface & - & - & 61 & 60 & 98 & 59 & 86 & 62 & 204 & 107 \\
\hline 20 & Surface & - & - & $1-$ & - & $1-$ & - & : - & - & 134 & 123 \\
\hline 21 & Subsurface & - & - & $1-$ & - & $1-$ & - & : - & - & $\begin{array}{l}92 \\
1\end{array}$ & 52 \\
\hline $22^{*}$ & Surface & - & - & 158 & 138 & 162 & 127 & $\begin{array}{l}159 \\
159\end{array}$ & 135 & 379 & 257 \\
\hline $23^{*}$ & Surface & - & - & 161 & 101 & 165 & 109 & 149 & 111 & 404 & 305 \\
\hline 24 & Subsurface & - & - & I 93 & 55 & 78 & 48 & 75 & 69 & 104 & 80 \\
\hline
\end{tabular}

Table 3: Crack sizes for vacuum sample LF006, where $2 c=$ surface length and $a=$ depth. Features 1 to 24 from top to bottom of gauge length; refer to Figure 7 (* indicates to the initiating features resulting in final failure). 


\section{List of Figures}

$1 \quad$ (a) Test piece schematic; (b) In situ synchrotron tomography high

725 temperature vacuum fatigue rig: 1 . actuator, 2. thermocouple feed-through, 3 . vacuum bellows, 4 . water cooling, 5 . quartz window, 6. power feed-through, 7. load cell, 8. alignment fixture, (c) Schematic cross-sectional view of the vacuum furnace, demonstrating the limited angle due to the pillar frame, (d) Ex situ lab-based tomography crack opening tensile rig. . . . . . . . . . . 25

730

2 (a) Principal component analysis axes; (b) Semi-circular crack

schematic, where $a$ is crack depth and $2 c$ is the surface length; (c) Fatigue crack 3D volume demonstrating principal components. 26

3 Backscatter electron images of the IMI 834 bimodal microstruc-

735 ture: (a) Bimodal microstructure; (b) Lamellar transformed beta

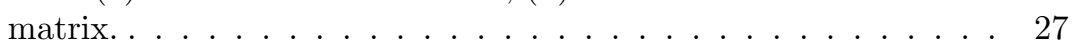

4 Mechanical testing data: (a) Tensile curve at $350^{\circ} \mathrm{C}$ in air, strain measured using high-temperature clip-on extensometer; (b) stress-

740 strain curves in air (LF015) and vacuum (LF006) for cycles 1 and

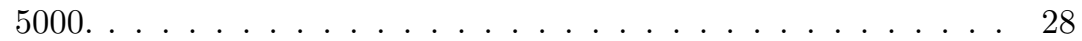

$5 \quad$ LF015 air crack growth data: (a) Surface feature 5; (b) Ratio of

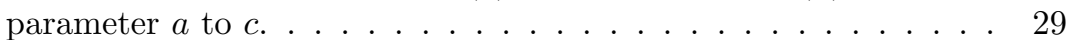

6 LF015 air sample: demonstrating the position of all features throughout the gauge of the sample after 11914 cycles $(235$ cycles

745

7 LF006 vacuum sample: demonstrating the position of all features throughout the gauge of the sample after 22726 cycles (478 cycles

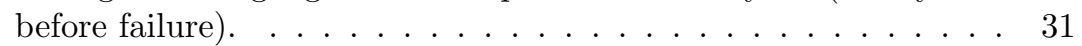

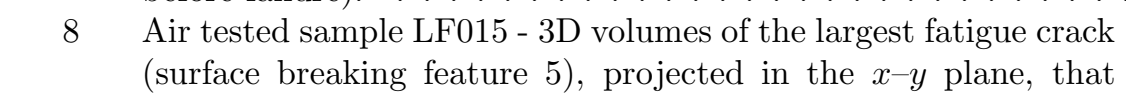

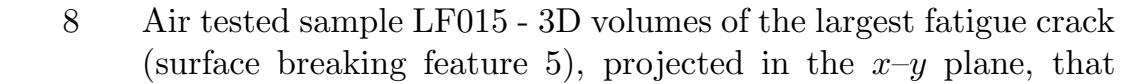

750 resulted in specimen failure at 12149 cycles. $\ldots \ldots \ldots . . \ldots 32$

$9 \quad$ Fractography of air tested sample LF015: (a) overview of the fracture surface (feature 5); (b) origin; (c) initiating facet; (d) secondary crack emanating from initiating facet; (e) striations

755 1 within the fatigue crack propagation zone (dotted) at $395 \mu \mathrm{m}$ from the origin; (f) subsurface secondary initiation site; (g) subsurface initiating facet; (h) microvoids distributed across the remainder of the fracture surface outside the fatigue crack initiation/propagation zone. . . . . . . . . . . . . . 33

10 LF006 vacuum crack growth data: (a,c) surface feature 22 and 760 1 $(\mathrm{b}, \mathrm{d})$ surface feature $23,(\mathrm{a}-\mathrm{b})$ crack sizes and (c-d) crack aspect

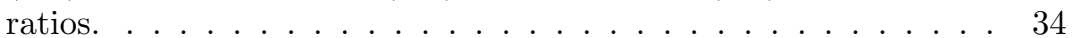

11 Vacuum sample LF006 - 3D volumes of the largest growing fatigue cracks that resulted in specimen failure at 23204 cycles: (a) Feature 22; (b) Feature 23. $\ldots \ldots \ldots \ldots \ldots$ 
12 Fractography of vacuum sample LF006: (a) overview of fracture surface - dotted lines represent primary fatigue initiation sites (features 22 and 23); (b) feature 23 origin; (c) feature 22 origin; (d) striations within fatigue crack propagation zone of feature

770 23 at $320 \mu \mathrm{m}$ from the origin; (e) subsurface initiating facet surrounded by microvoids; (f) subsurface facet dimensions of the

order of globular primary $\alpha$ grains; (g) structure evident on the surface of the subsurface facet; (h) microvoids distributed across the remainder of the fracture surface outside the fatigue crack initiation/propagation zone. . . . . . . . . . . . . . . 36

775 Vacuum sample LF006 - 3D volumes of a subsurface fatigue crack (feature 17) at 22726 cycles. . . . . . . . . . . . . . . . . . 37

14 LF006 vacuum crack growth data: (a) Subsurface feature 17; (b) Ratio of parameter $a$ to $c$. . . . . . . . . . . . . . 38

780

$15 x-z$ slices with $z=$ loading direction $-(\mathrm{a})$ synchrotron data, (b) and (c) laboratory data: (a) Air sample (LF015) surface feature 5 at $N=11,914$; (b) Vacuum sample (LF006) surface feature 23 at $N=22,726$; (c) Vacuum sample (LF006) subsurface feature 17 at $N=22,726$. 

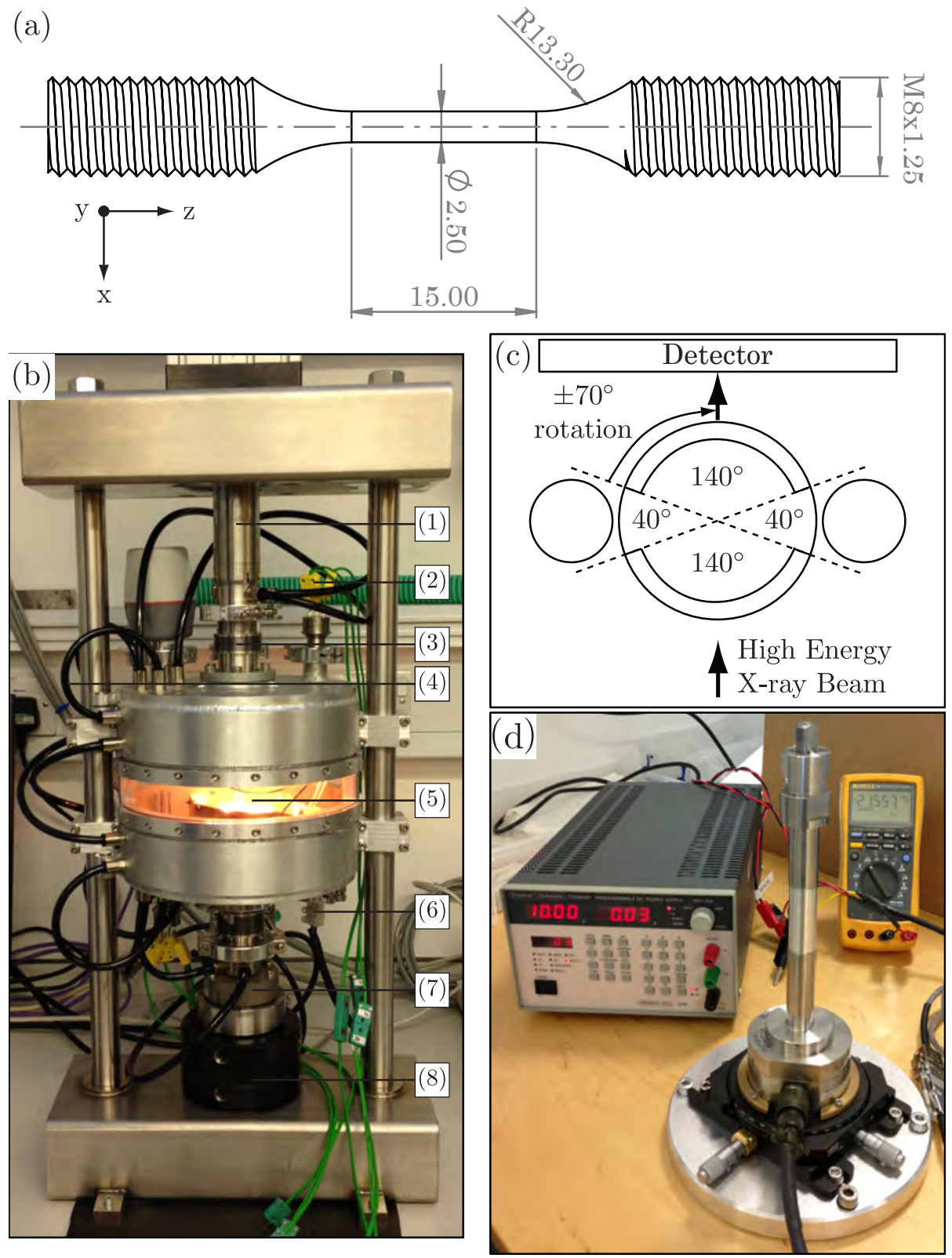

Figure 1: (a) Test piece schematic; (b) In situ synchrotron tomography high temperature vacuum fatigue rig: 1 . actuator, 2 . thermocouple feed-through, 3 . vacuum bellows, 4 . water cooling, 5. quartz window, 6. power feed-through, 7. load cell, 8. alignment fixture, (c) Schematic cross-sectional view of the vacuum furnace, demonstrating the limited angle due to the pillar frame, (d) Ex situ lab-based tomography crack opening tensile rig. 


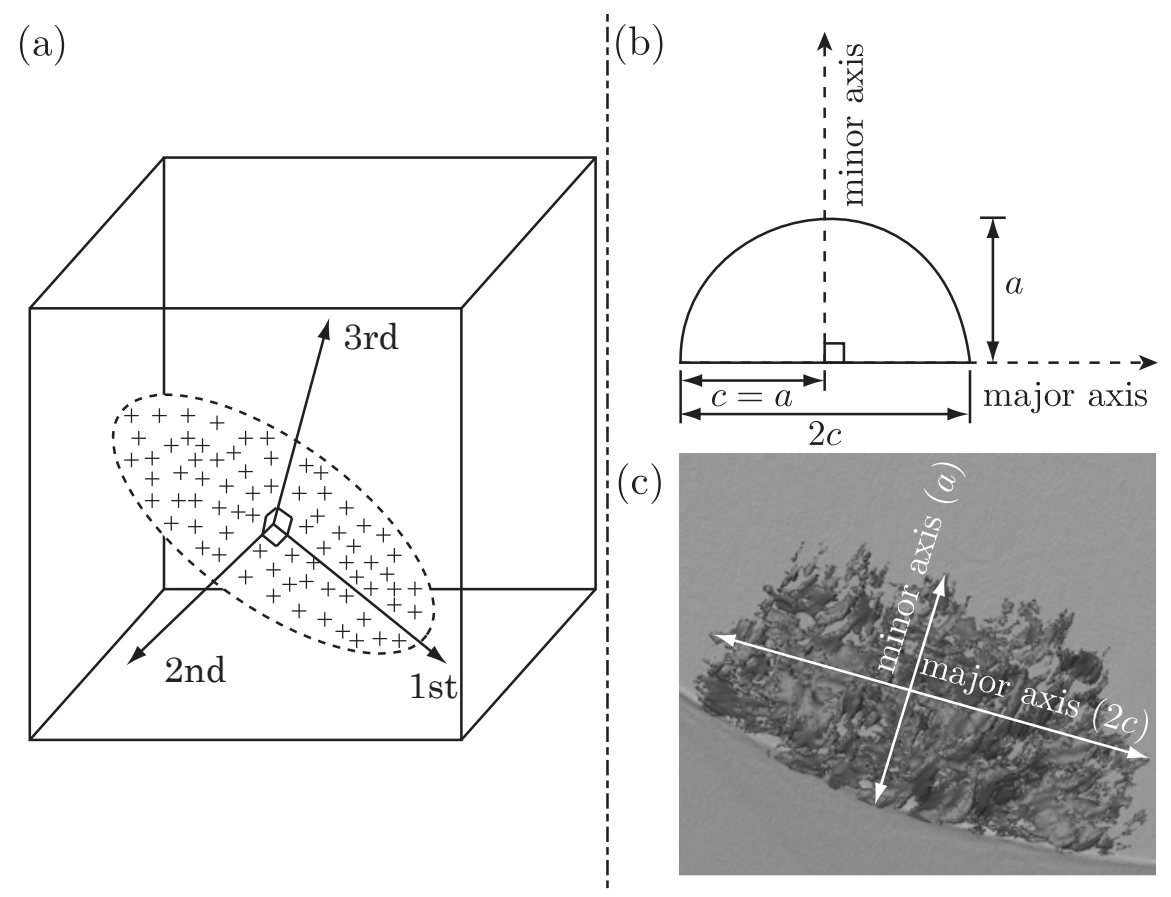

Figure 2: (a) Principal component analysis axes; (b) Semi-circular crack schematic, where $a$ is crack depth and $2 c$ is the surface length; (c) Fatigue crack $3 \mathrm{D}$ volume demonstrating principal components. 

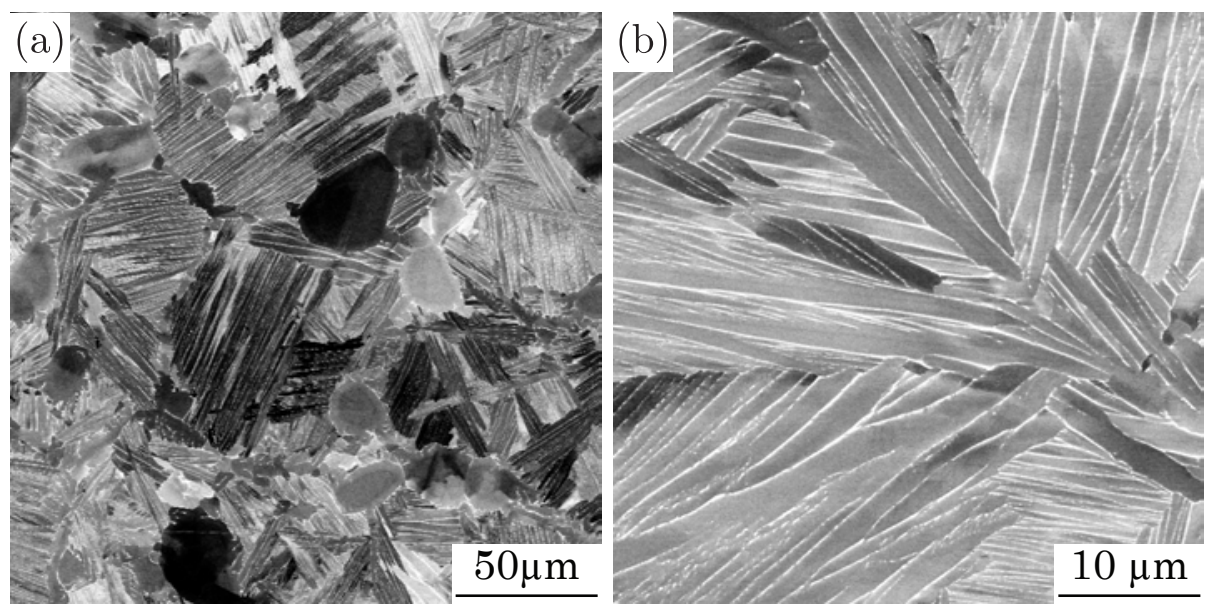

Figure 3: Backscatter electron images of the IMI 834 bimodal microstructure: (a) Bimodal microstructure; (b) Lamellar transformed beta matrix. 
(a)

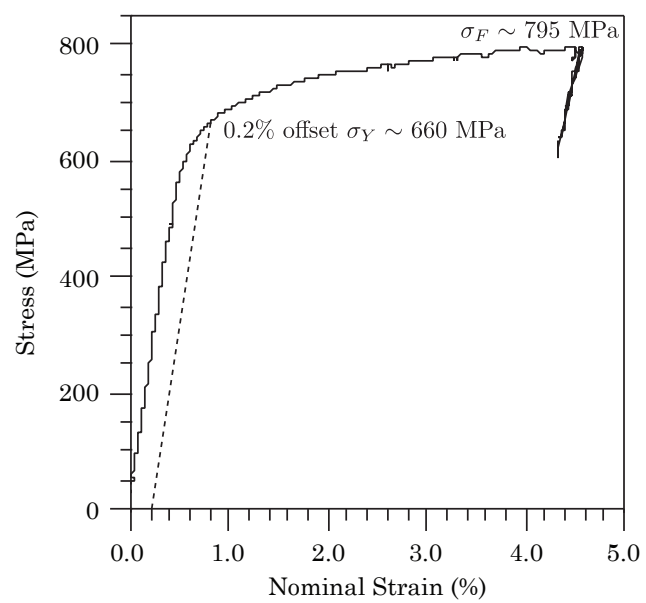

(b)

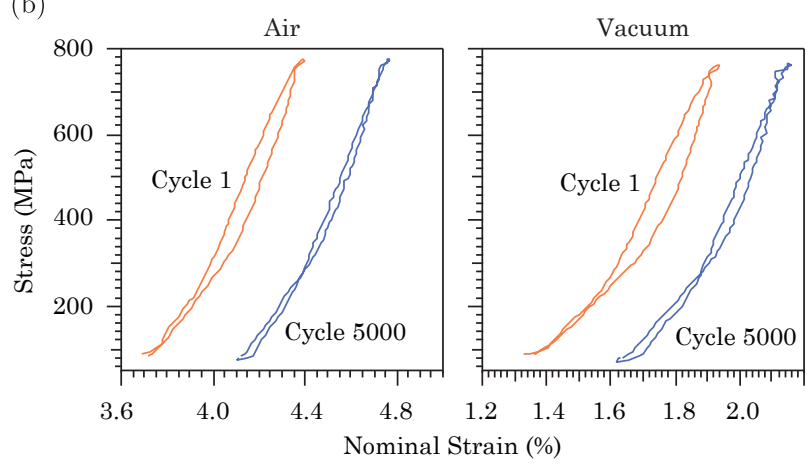

Figure 4: Mechanical testing data: (a) Tensile curve at $350{ }^{\circ} \mathrm{C}$ in air, strain measured using high-temperature clip-on extensometer; (b) stress-strain curves in air (LF015) and vacuum (LF006) for cycles 1 and 5000. 
(a)

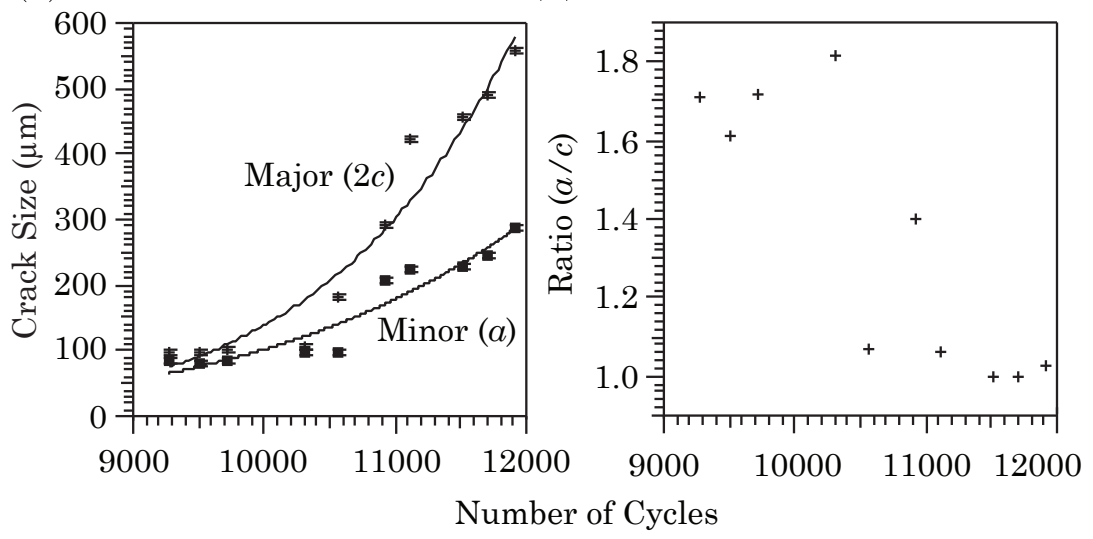

Figure 5: LF015 air crack growth data: (a) Surface feature 5; (b) Ratio of parameter $a$ to $c$. 

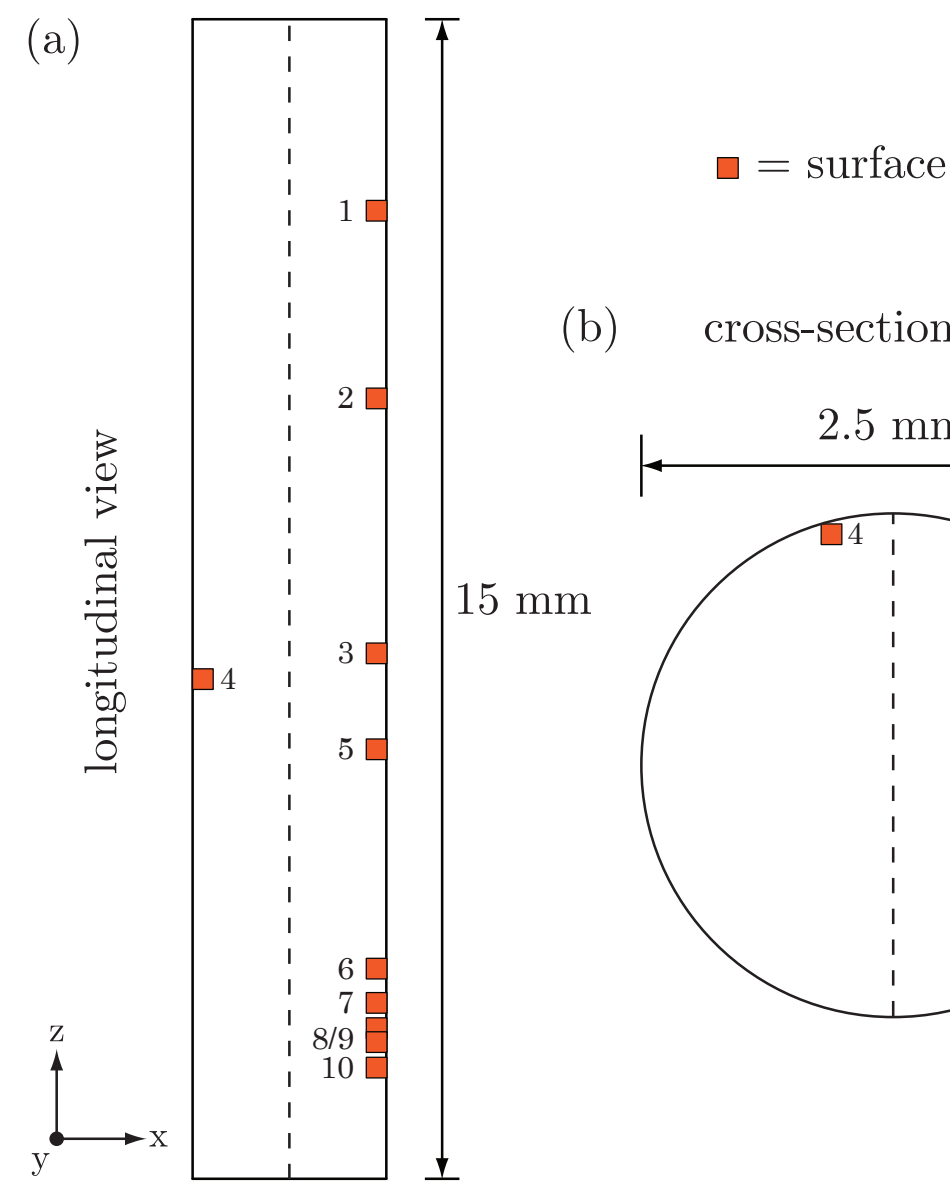

(b) cross-sectional view

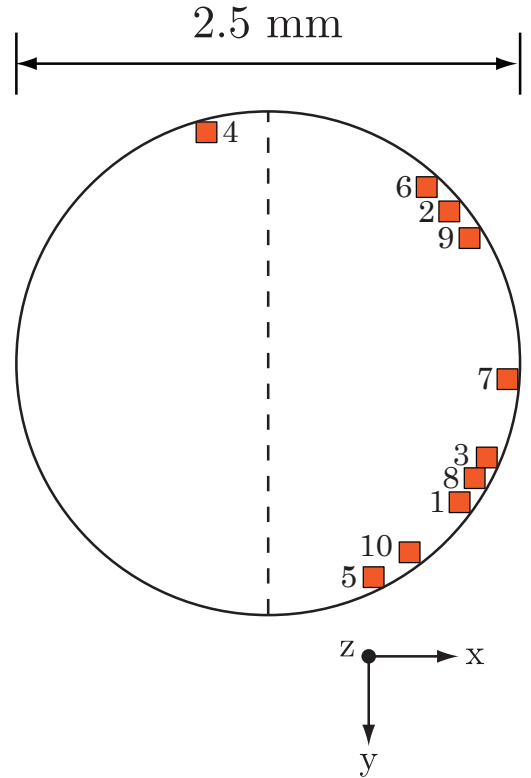

Figure 6: LF015 air sample: demonstrating the position of all features throughout the gauge of the sample after 11914 cycles (235 cycles before failure). 
(a)

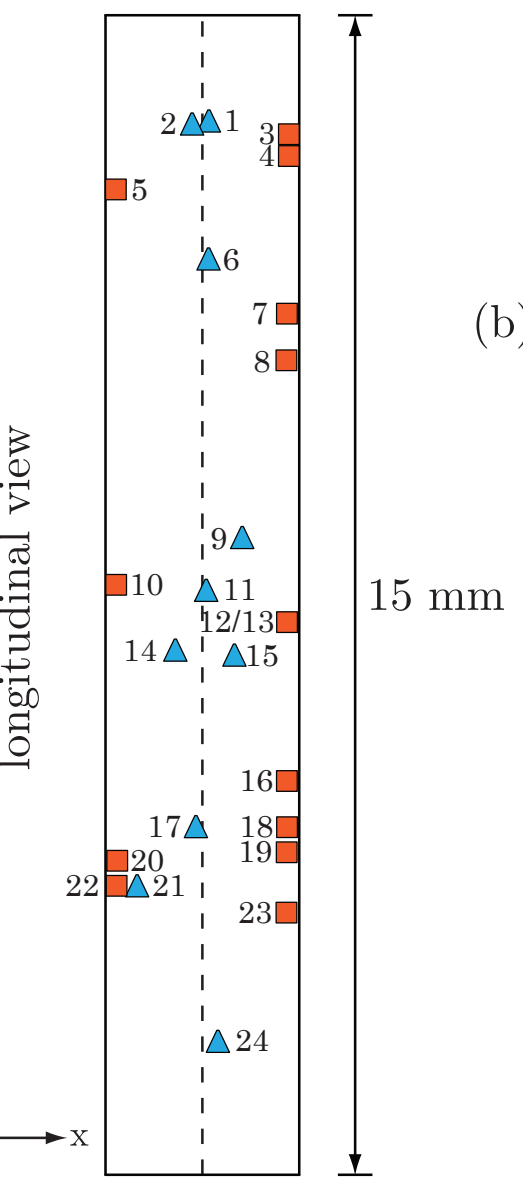

$\square=$ surface

$\Delta=$ subsurface

(b) cross-sectional view

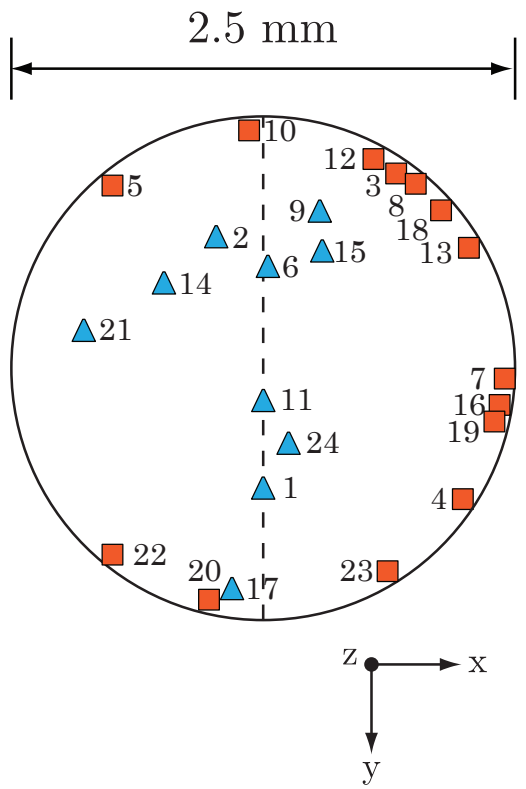

Figure 7: LF006 vacuum sample: demonstrating the position of all features throughout the gauge of the sample after 22726 cycles ( 478 cycles before failure). 


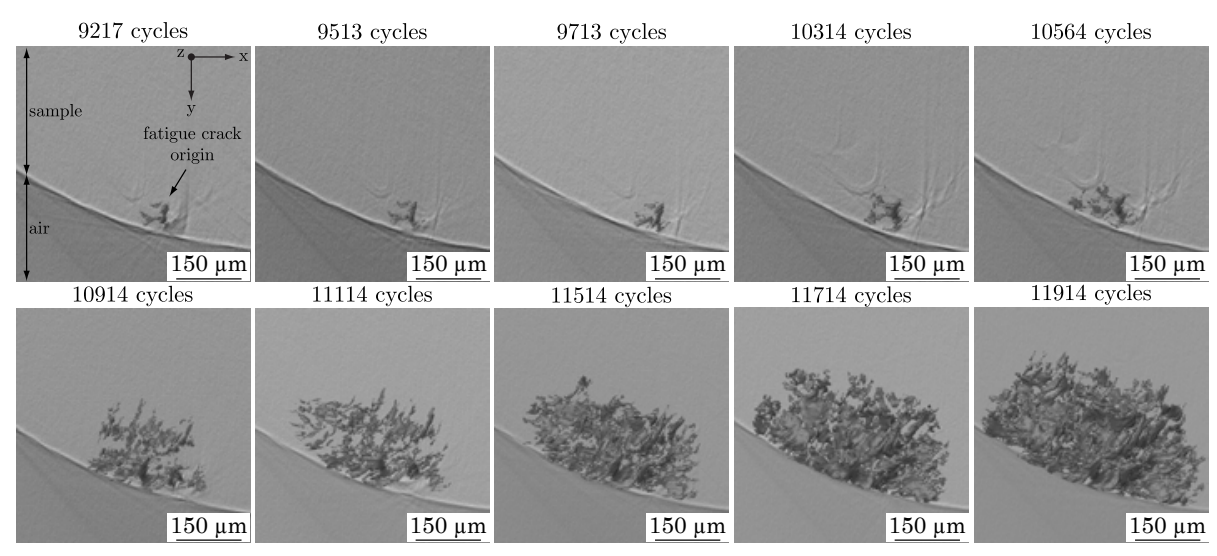

Figure 8: Air tested sample LF015 - 3D volumes of the largest fatigue crack (surface breaking feature 5), projected in the $x-y$ plane, that resulted in specimen failure at 12149 cycles. 

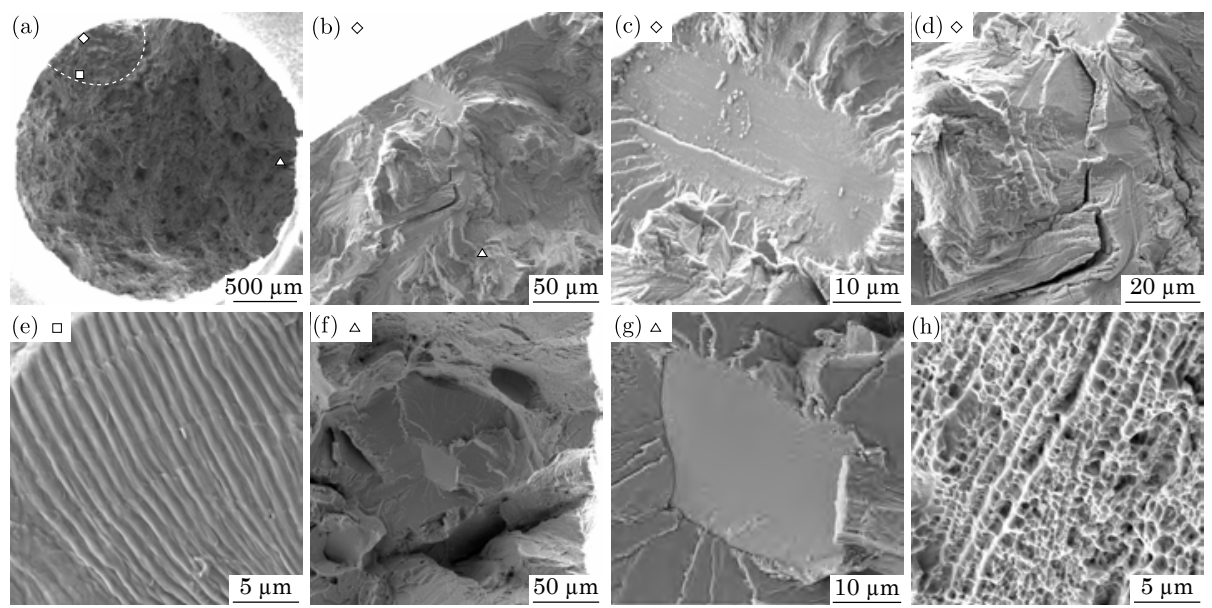

Figure 9: Fractography of air tested sample LF015: (a) overview of the fracture surface (feature 5); (b) origin; (c) initiating facet; (d) secondary crack emanating from initiating facet; (e) striations within the fatigue crack propagation zone (dotted) at $395 \mu \mathrm{m}$ from the origin; (f) subsurface secondary initiation site; (g) subsurface initiating facet; (h) microvoids distributed across the remainder of the fracture surface outside the fatigue crack initiation/propagation zone. 
(a)

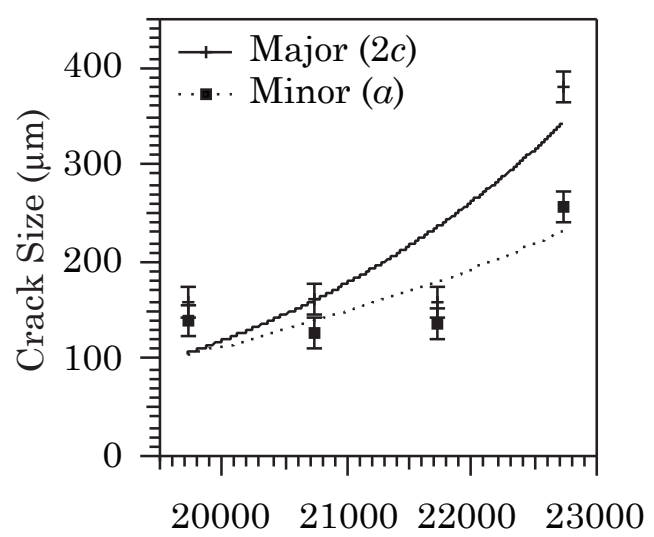

(b)

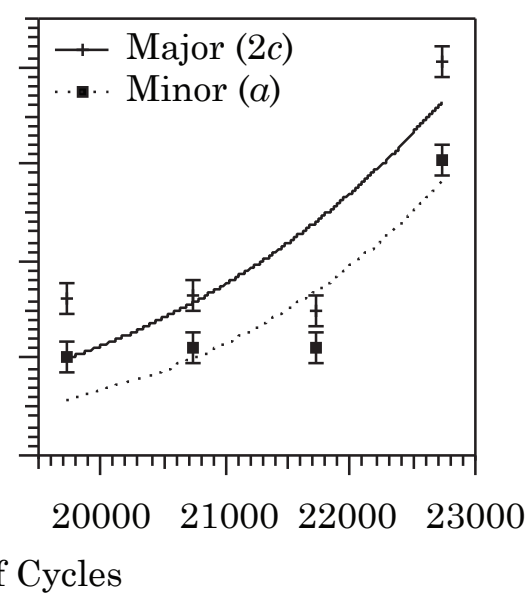

(d)

(c)
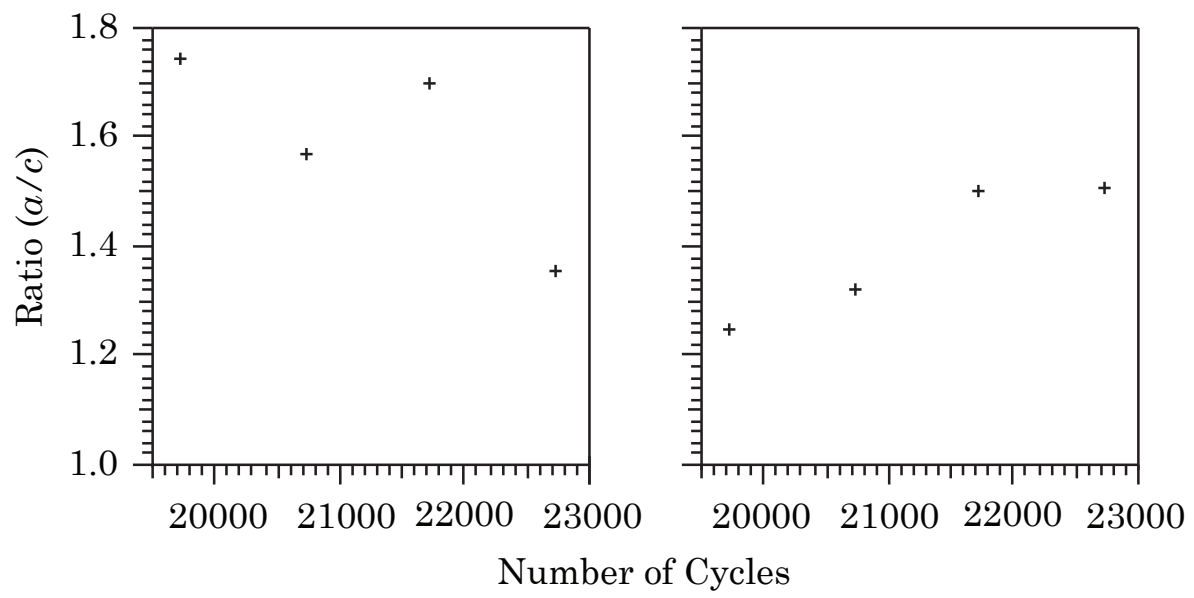

Figure 10: LF006 vacuum crack growth data: (a,c) surface feature 22 and (b,d) surface feature 23, (a-b) crack sizes and (c-d) crack aspect ratios. 

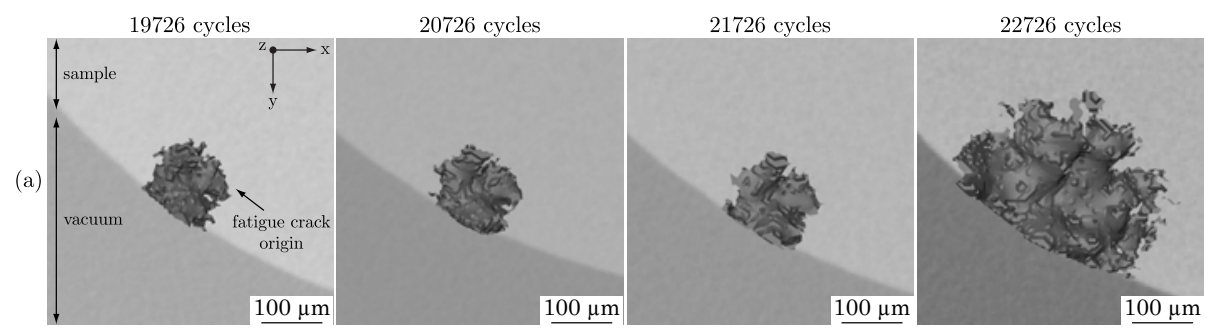

(b)
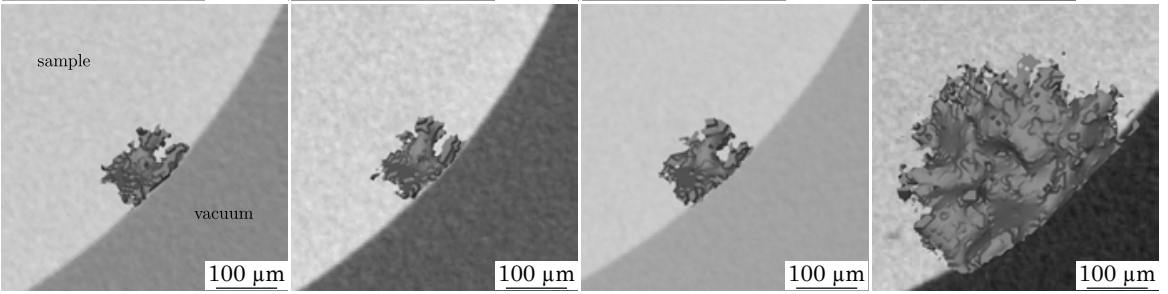

Figure 11: Vacuum sample LF006 - 3D volumes of the largest growing fatigue cracks that resulted in specimen failure at 23204 cycles: (a) Feature 22; (b) Feature 23. 

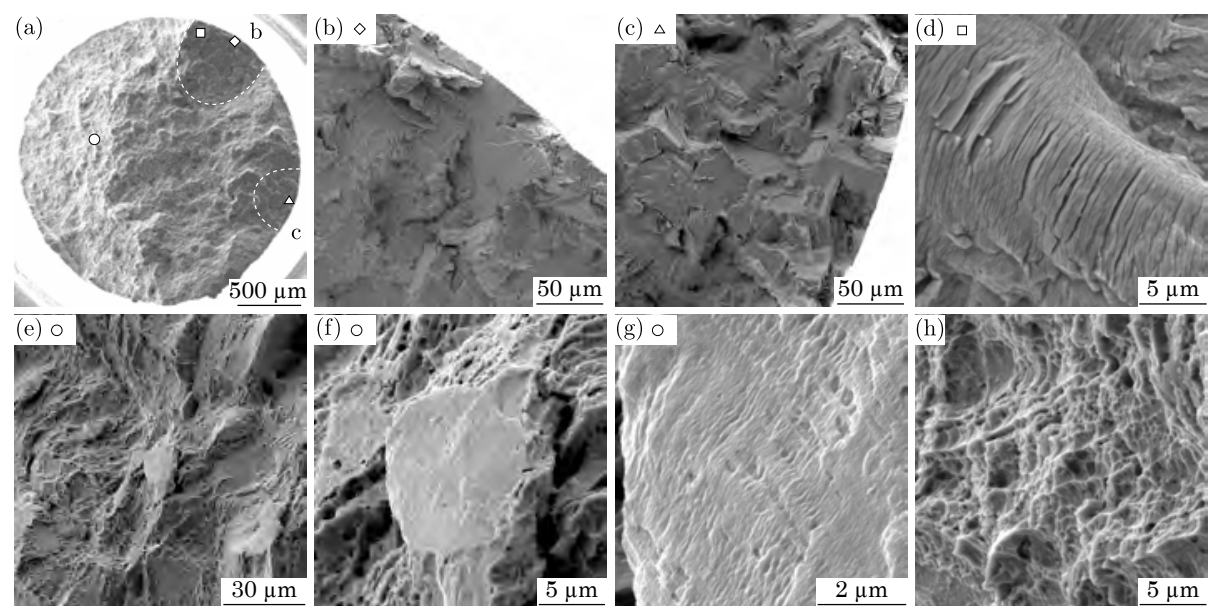

Figure 12: Fractography of vacuum sample LF006: (a) overview of fracture surface - dotted lines represent primary fatigue initiation sites (features 22 and 23); (b) feature 23 origin; (c) feature 22 origin; (d) striations within fatigue crack propagation zone of feature 23 at $320 \mu \mathrm{m}$ from the origin; (e) subsurface initiating facet surrounded by microvoids; (f) subsurface facet dimensions of the order of globular primary $\alpha$ grains; (g) structure evident on the surface of the subsurface facet; (h) microvoids distributed across the remainder of the fracture surface outside the fatigue crack initiation/propagation zone. 


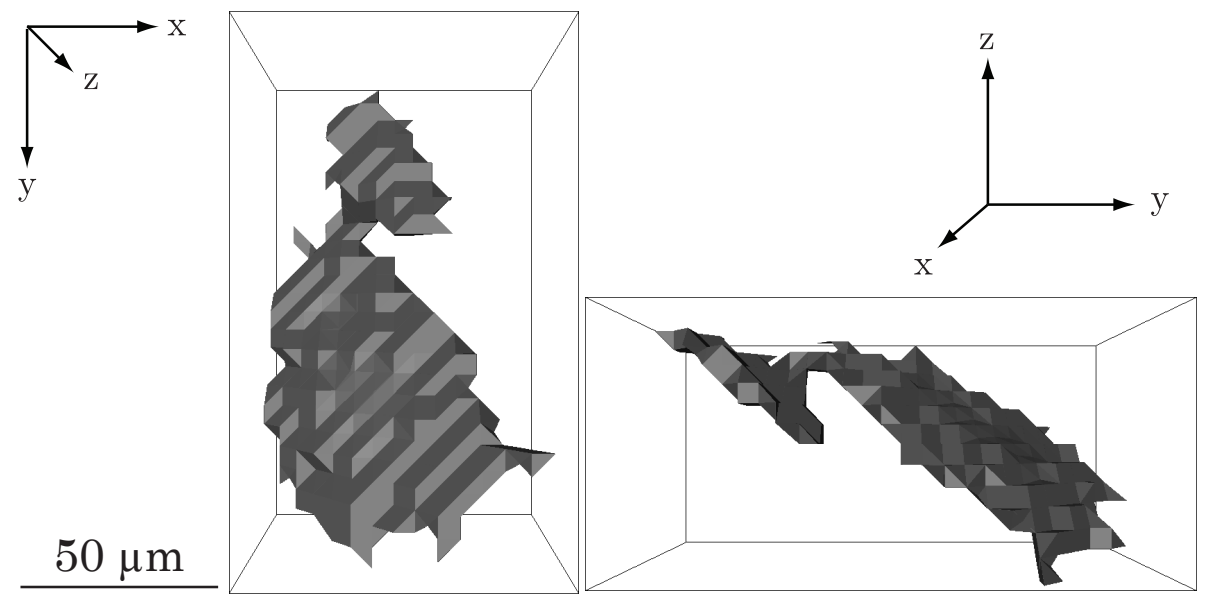

Figure 13: Vacuum sample LF006 - 3D volumes of a subsurface fatigue crack (feature 17) at 22726 cycles. 
(a)

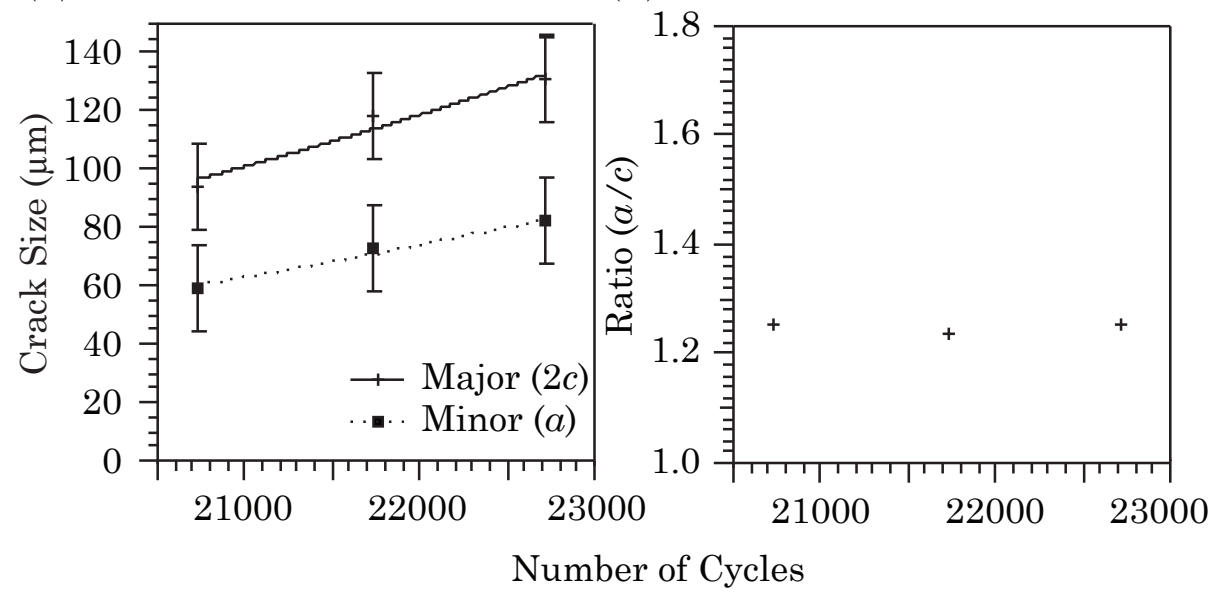

Figure 14: LF006 vacuum crack growth data: (a) Subsurface feature 17; (b) Ratio of parameter $a$ to $c$.

(b) 

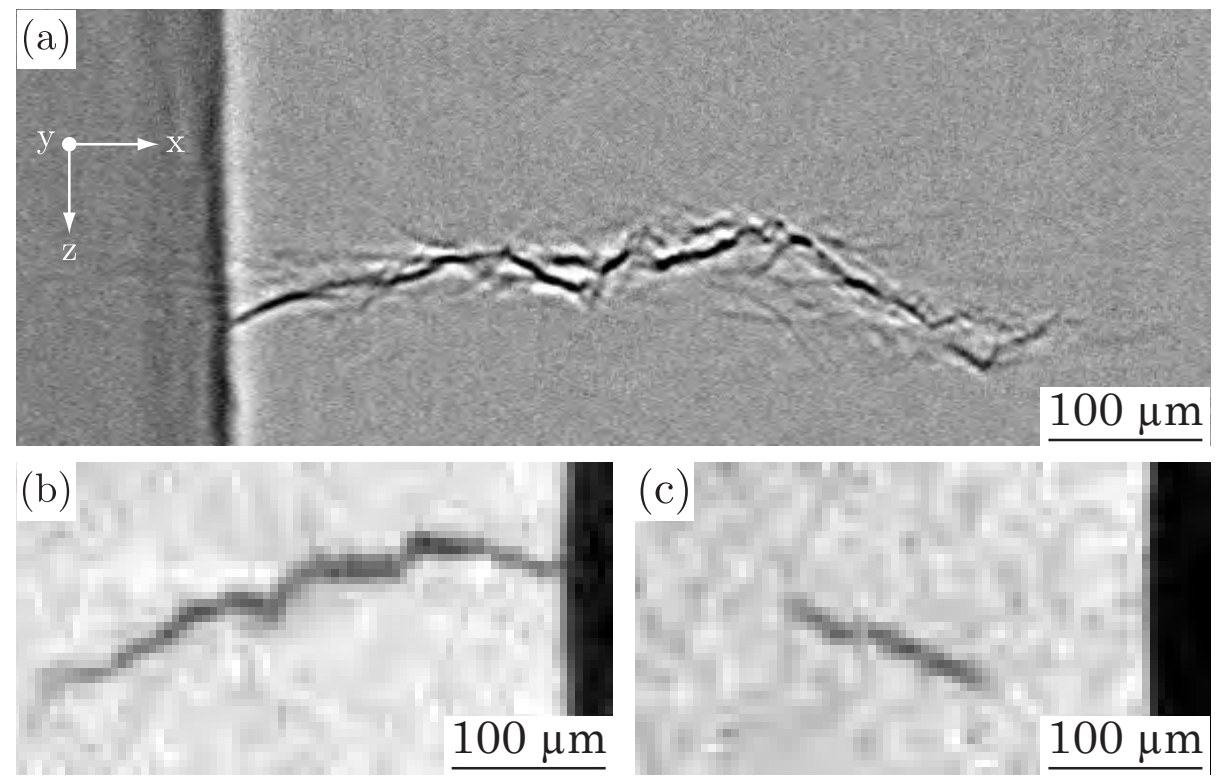

Figure 15: $x-z$ slices with $z=$ loading direction - (a) synchrotron data, (b) and (c) laboratory data: (a) Air sample (LF015) surface feature 5 at $N=11,914$; (b) Vacuum sample (LF006) surface feature 23 at $N=22,726$; (c) Vacuum sample (LF006) subsurface feature 17 at $N=22,726$. 